\title{
EFFECT OF IN VIVO JET FUEL EXPOSURE ON SUBSEQUENT IN VITRO DERMAL ABSORPTION OF INDIVIDUAL AROMATIC AND ALIPHATIC HYDROCARBON FUEL CONSTITUENTS
}

\author{
F. Muhammad, N. A. Monteiro-Riviere, R. E. Baynes, J. E. Riviere \\ Center for Chemical Toxicology Research and Pharmacokinetics, College \\ of Veterinary Medicine, North Carolina State University, Raleigh, North \\ Carolina, USA
}

\begin{abstract}
The percutaneous absorption of topically applied jet fuel hydrocarbons (HC) through skin previously exposed to jet fuel has not been investigated, although this exposure scenario is the occupational norm. Pigs were exposed to JP-8 jet fuel-soaked cotton fabrics for 1 and $4 d$ with repeated daily exposures. Preexposed and unexposed skin was then dermatomed and placed in flow-through in vitro diffusion cells. Five cells with exposed skin and four cells with unexposed skin were dosed with a mixture of 14 different HC consisting of nonane, decane, undecane, dodecane, tridecane, tetradecane, pentadecane, hexadecane, ethyl benzene, o-xylene, trimethyl benzene (TMB), cyclohexyl benzene (CHB), naphthalene, and dimethyl naphthalene $(D M N)$ in water + ethanol (50:50) as diluent. Another five cells containing only JP-8-exposed skin were dosed solely with diluent in order to determine the skin retention of jet fuel HC. The absorption parameters of flux, diffusivity, and permeability were calculated for the studied HC. The data indicated that there was a two-fold and four-fold increase in absorption of specific aromatic HC like ethyl benzene, o-xylene, and TMB through 1- and 4-dJP-8 preexposed skin, respectively. Similarly, dodecane and tridecane were absorbed more in 4-d than 1-dJP-8 preexposed skin experiments. The absorption of naphthalene and DMN was 1.5 times greater than the controls in both 1- and 4-d preexposures. CHB, naphthalene, and DMN had significant persistent skin retention in 4-d preexposures as compared to 1-d exposures that might leave skin capable of further absorption several days postexposure. The possible mechanism of an increase in HC absorption in fuel preexposed skin may be via lipid extraction from the stratum corneum as indicated by Fourier transform infrared (FTIR) spectroscopy. This study suggests that the preexposure of skin to jet fuel enhances the subsequent in vitro percutaneous absorption of HC, so single-dose absorption data for jet fuel HC from naive skin may not be optimal to predict the toxic potential for repeated exposures. For certain compounds, persistent absorption may occur days after the initial exposure.
\end{abstract}

Different jet fuels contain different additives based on the performance requirements of the aircraft. The principal difference between fuels is the freezing and flash-point specifications. Military aircraft fly under extreme

Received 11 August 2004; accepted 22 October 2004.

This work was supported by U.S. Air Force Office of Scientific Research, grant F49620-01-1-0080.

Current address for F. Muhammad is Faculty of Veterinary Science, University of Agriculture, Faisalabad, Pakistan.

Address correspondence to Dr. Jim E. Riviere, Center for Chemical Toxicology Research and Pharmacokinetics, College of Veterinary Medicine, North Carolina State University, Raleigh, NC 27695, USA. E-mail: Jim_Riviere@ncsu.edu 
conditions compared with commercial or civilian aircraft, requiring specific additives to the basic hydrocarbon fuel components of Jet A (commercial fuel) to increase performance (White, 1999). JP-8 jet fuel is the standard military fuel for all types of vehicles, including the U.S. Air Force aircraft inventory. As such, JP-8 presents the most common chemical exposure in the Air Force, particularly for flight and ground crew personnel during preflight operations and for maintenance personnel performing routine tasks. Personal exposure at an Air Force base occurs through occupational exposure for personnel involved with fuel and aircraft handling and/or through incidental exposure, primarily through inhalation of ambient fuel vapors. Because JP-8 is less volatile than its predecessor fuel (JP-4), contact with liquid fuel on skin and clothing may result in prolonged exposure. The slowly evaporating JP-8 fuel tends to linger on exposed personnel during their interaction with previously unexposed colleagues, providing an additional potential route for exposure (Pleil et al., 2000). JP-8 has the potential to induce local and systemic toxicity from cutaneous exposures (McDougal \& Rogers, 2004). Neurological effects and irritant dermatitis have been reported in workers exposed to JP-8 jet fuel (Zeiger \& Smith, 1998; Smith et al., 1997). Significant effects on the immune, hepatic, neurological, and respiratory systems have been observed in several animal exposure studies (Grant et al., 2000; Harris et al., 2000; Robledo et al., 2000).

Topical application of jet fuels can produce gross morphological changes in porcine skin (Monteiro-Riviere et al., 2001; Rhyne et al., 2002), and can release tumor necrosis factor- $\alpha$ and interleukin-8 (IL-8) in cultured human epidermal keratinocytes (HEK) and in porcine keratinocytes (Allen et al., 2000, 2001). Different aliphatic and aromatic HC are found to induce IL-8 release from HEK (Chou et al., 2002, 2003). These findings suggest that toxic components in jet fuels readily penetrate skin to elicit these dermatological effects. Several dermal absorption studies in rats (McDougal et al., 2000) and porcine skin flaps and skin sections (Riviere et al., 1999; Baynes et al., 2001) have assessed the dermal disposition of several jet fuel components and additives.

The crews working on jet engine fuel tank maintenance wear fuel-permeable cotton coveralls to reduce the possibility of explosion due to the generation of static electricity associated with more protective clothing. Daily exposure to fuels results in saturation of the cotton cloth, resulting in an occluded environment for repeated, long-term exposure to the skin during the typical 8-h workday (Allen et al., 2001). Chronic exposure to jet fuel has been shown to produce human liver dysfunction, emotional dysfunction, abnormal electroencephalograms, shortened attention spans, decreased sensorimotor speed, and changes in immune functions (Harris et al., 2001). Repeated application of petroleum middle distillates to the skin produces chronic irritation and inflammation (Freeman et al., 1990; Grasso et al., 1988). Fabric soaked with jet fuels for $4 \mathrm{~d}$ and evaluated on $\mathrm{d} 5$ produced significant skin damage in pigs (Monteiro-Riviere et al., 2001). The disruption of barrier function of skin, as indicated by an increase in transepidermal water loss after exposure to JP-8, might result in increased permeation of its own components and/or other 
chemicals exposed to skin (Kanikkannan et al., 2001a; Monteiro-Riviere et al., 2001). Preexposure of skin to laurocapram, a compound similar to some of the JP-8 performance additives, enhanced the penetration of sodium lauryl sulfate (SLS), suggesting that an increase in irritation at the exposed site is possible (Szolar-Platzer et al., 1996).

Studies showed a dose-related increase in the percutaneous absorption of the jet fuel aromatic HC with hexadecane (a fuel constituent) as a solvent (Muhammad et al., 2004). Repeated daily exposure to jet fuels is the more likely scenario in an occupational setting. There is no available information on percutaneous absorption of jet fuel components after repeated exposure or preexposure to fuel. Understanding this process is necessary to interpret pertinent exposure data and to minimize hazardous health risks in humans. Are skin-retained $\mathrm{HC}$ from past fuel exposure susceptible to mobilization by subsequent aqueous solvent exposure? Do such retained HC modify subsequent $\mathrm{HC}$ absorption? The present study was designed to assess the in vitro percutaneous absorption of a mixture of 14 selected jet fuel $\mathrm{HC}$ after single and repeated in vivo exposures to JP-8. This study used a polar solvent, in contrast to a nonpolar one such as hexadecane, which may enhance the dermal penetration of fuel hydrocarbons to allow for easy detection in perfusate samples. Specifically, this study was conducted to determine the following:

Whether in vivo preexposure of skin to jet fuel would affect the subsequent in vitro percutaneous absorption of selected marker components.

Whether single-dose application data from naive (control) skin for jet fuel marker $\mathrm{HC}$ can be used to predict the dermal penetration after repeated exposures.

\section{MATERIALS AND METHODS}

\section{In Vivo Exposure Experiments}

Female weanling Yorkshire pigs (4-8 wk old, 35-45 lb) obtained from local breeders were used in these experiments. One animal was used for each in vitro flow-through experiment. All in vivo exposures were conducted according to Institutional Animal Care and Use Committee (IACUC) guidelines. In order to mimic occupational exposure conditions, prewashed cotton fabric strips $(25 \times 8 \mathrm{~cm})$ were used to expose the pigs to JP-8 jet fuel and covered an area of $12 \times 8 \mathrm{~cm}$. Pigs were sedated with an intramuscular injection of ketamine/xylazine/telazol and hairs were clipped from the back $24 \mathrm{~h}$ before dosing. In total, four cotton fabric strips were used on each pig. Two of them were dosed with $2 \mathrm{ml} \mathrm{JP}-8$ in the middle of the strip to saturate the marked dosing area in 1-d in vivo exposures. These two dosed strips were redosed with the same amount of JP-8 on d 2, 3, and 4 after the first application in the 4-d exposure study. The other two strips were used as controls. All the strips were removed from the body of the pig after $24 \mathrm{~h}$ and after $4 \mathrm{~d}$ of JP-8 application 
in 1- and 4-d exposures respectively. One dosed and nondosed area was dermatomed for diffusion skin flow through experiments. The same control and exposed sites were used for each experiment.

\section{In Vitro Flow-Through Experiments}

The flow-through diffusion cell system, as previously described by Bronaugh and Stewart (1985), was used to perfuse porcine skin. The skin was dermatomed to a thickness of $500 \mu \mathrm{m}$ with a Padgett dermatome (Padgett Instruments, Kansas City, MO). This thickness was employed to ensure that the base of hair follicles was not sectioned. The skin was trimmed to provide a dosing surface area of $0.64 \mathrm{~cm}^{2}$ and then placed into a two-compartment Teflon flow-through diffusion cell (Crowne Glass, Sommerville, NJ). For these experiments, eight aliphatic (nonane, decane, undecane, dodecane, tridecane, tetradecane, pentadecane, hexadecane) and six aromatic (ethyl benzene, o-xylene, trimethyl benzene, cyclohexyl benzene, naphthalene, dimethyl naphthalene) hydrocarbons were used as dosing mixture with water + ethanol (50:50) as the diluent. The dosing mixture was comprised of nonane (288 $\mu \mathrm{g})$, decane $(292 \mu \mathrm{g})$, undecane $(1236.6 \mu \mathrm{g})$, dodecane $(1410 \mu \mathrm{g})$, tridecane $(1320$ $\mu \mathrm{g})$, tetradecane $(912 \mu \mathrm{g})$, pentadecane $(492.8 \mu \mathrm{g})$, hexadecane $(308 \mu \mathrm{g})$, naphthalene $(510.4 \mu \mathrm{g})$, dimethyl naphthalene $(526.8 \mu \mathrm{g})$, ethyl benzene (346.8 $\mu \mathrm{g}), o$-xylene $(348 \mu \mathrm{g})$, cyclohexyl benzene $(380 \mu \mathrm{g})$, and trimethyl benzene $(355.6 \mu \mathrm{g})$ per diffusion cell in water + ethanol (50:50) as solvent. Aqueous ethanol was selected as a solvent to ensure detection of topically applied HCs in perfusates. A total of $20 \mu$ of this dosing mixture was dosed topically in diffusion flow-through cells. This dosing concentration was selected for better chromatographic detection for most of selected HC in perfusates (Muhammad et al., 2004). The skin flow-through diffusion cells were dosed separately in the following order for both 1 - and 4-d exposure experiments: first 5 cells (preexposed skin + dosing mixture); next 5 cells (preexposed skin + diluent only in order to access the skin retention of jet fuel $\mathrm{HC}$ ); last 4 cells (control skin not preexposed to JP-8 from the same pig + dosing mixture).

Skin flow-through cells were perfused with Krebs-Ringer bicarbonate buffer with dextrose $(0.12 \%)$ and bovine serum albumin $(4.5 \%)$. The temperature of the perfusate and flow-through cell was maintained at $37^{\circ} \mathrm{C}$ using a Brinkmann constant temperature circulator (Brinkmann, Westbury, NY). The $\mathrm{pH}$ of perfusate was maintained between 7.4 and 7.5. Perfusate flow rate was $4 \mathrm{ml} / \mathrm{h}$. Sampling was accomplished in an open-air system using an automated fraction collector (ISCO Retriever IV, Lincoln, NE). Perfusate samples were taken at $0,10,20,30,45,60,75,90,105,120,150,180,240$, and $300 \mathrm{~min}$ and saved immediately in a freezer until chromatographic analysis.

\section{Chromatographic Analysis}

Solid-phase microextraction (SPME) fiber with headspace sampling was used to assay the perfusates as described previously (Muhammad et al., 2004). Chromatographic analysis was performed on a gas chromatograph (GC) 5890 
(Hewlett Packard series II) equipped with a flame ionization detector (FID). The sensitivity of GC-FID for all the standards was $0.1 \mu \mathrm{g} / \mathrm{ml}$. The limit of detectability in samples with SPME fiber was $0.1-1 \mathrm{ng} / \mathrm{ml}$ for short-chain aliphatic and $5 \mathrm{ng} / \mathrm{ml}$ for aromatic HC. GC-FID conditions were as follows: DB-5 capillary column $(30 \mathrm{~m} \times 0.25 \mathrm{~mm}$ ID, $0.25 \mu \mathrm{m}$ film thickness; J \& W Scientific); injection port temperature, $280^{\circ} \mathrm{C}$; detector temperature, $300^{\circ} \mathrm{C}$; oven temperature, $40-280^{\circ} \mathrm{C}$ (held at $40^{\circ} \mathrm{C}$ for $3 \mathrm{~min}$, then increased at $8^{\circ} \mathrm{C} / \mathrm{min}$ up to $160^{\circ} \mathrm{C}$, then at $30^{\circ} \mathrm{C} / \mathrm{min}$ up to the final temperature of $280^{\circ} \mathrm{C}$ for $1 \mathrm{~min}$ ); carrier gas (helium) flow rate, $1.24 \mathrm{ml} / \mathrm{min}$; carrier + makeup gas $(\mathrm{He})$ flow rate, $22.5 \mathrm{ml} / \mathrm{min}$; hydrogen flow rate, $45 \mathrm{ml} / \mathrm{min}$; air flow rate, $300-320 \mathrm{ml} / \mathrm{min}$. SPME devices and 100- $\mu \mathrm{m}$ polydimethylsiloxane (PDMS) fiber assemblies were purchased from Supelco (Bellefonte, PA).

\section{Standard Curves}

Stock solutions of each of the tested hydrocarbons were prepared individually in acetone. All stock solutions were mixed together and serially diluted in acetone to yield concentrations of $10,5,2.5,1,0.5$, and $0.1 \mu \mathrm{g} / \mathrm{ml}$. Equal volumes of perfusion media were spiked with each of these concentrations to have standard solutions of 1000,500, 250, 100, 50, and $10 \mathrm{ng} / \mathrm{ml}$ of media accordingly; $300 \mu \mathrm{l}$ from each of these standard solutions was drawn into GC glass vials. A tiny stir bar was placed into each vial, which was sealed and exposed to head space (HS) SPME fiber for $25 \mathrm{~min}$ at $37^{\circ} \mathrm{C}$ along with continuous stirring. The SPME fiber was then injected into the GC and held for $5 \mathrm{~min}$. The peak areas obtained were then plotted against standard concentrations, and linear relationships with good correlation coefficients were obtained for all the tested hydrocarbons. The same procedure was adopted for the analysis of perfusate samples.

\section{FTIR Experiments With the Stratum Corneum}

Stratum corneum (SC) sheets were prepared from the dissected porcine skin according to the method described by Baynes et al. (2000). Briefly, the dissected skin was trimmed to fit between preheated aluminum blocks and placed in an oven at $60^{\circ} \mathrm{C}$ for $6-8 \mathrm{~min}$. The SC/epidermis was removed using dissection forceps and placed dermis side down into petri dishes lined with filter paper and containing 0.25\% trypsin (Sigma) to dissolve the epidermis. After $24 \mathrm{~h}$ in an incubation oven at $35^{\circ} \mathrm{C}$, trypsin inhibitor (Sigma) was added to neutralize trypsin and the SC was washed with distilled water. The SC was dried at room temperature for $24 \mathrm{~h}$ and then in a desiccator for $48 \mathrm{~h}$. We used dried SC sheets for Fourier transform infrared (FTIR) analysis based on previous studies of Panchagnula et al. (2001), Levang et al. (1999), and Potts and Francoeur (1992), who used dried SC sheets for evaluation of lipids. Hydrated tissues cannot be evaluated with FTIR since this instrument utilizes a transmission beam. If there is water in the tissue, it will absorb all the infrared energy and significantly alter the infrared spectrum. The dried SC discs were scanned by a Fourier transform infrared (FTIR) spectrometer (Spectrum 1000, Perkin 
Elmer Instruments, Shelton, CT) and placed in vials. About $2 \mathrm{ml}$ of each of the tested hydrocarbons was added to the SC sample vials $(n=4)$, which were capped, sealed, and allowed to remain undisturbed at room temperature for $24 \mathrm{~h}$. At $24 \mathrm{~h}$, each SC sample was removed and placed under a hood overnight, and then in a desiccator for $48 \mathrm{~h}$ to dry it completely. Dried SC samples were scanned again with FTIR and compared with the respective scans before treatment. The FTIR peak heights and widths were analyzed with Spectrum software by Perkin Elmer Instruments (Shelton, CT).

\section{Calculations and Statistics}

The perfusate concentrations $(\mathrm{ng} / \mathrm{ml})$ were determined for the different dosing protocols. Absorption was defined as the total amount (ng) detected in the perfusate for the entire 5-h perfusion period. Absorption parameters of flux, permeability, and diffusivity were calculated as follows. Flux $\left(\mu \mathrm{g} / \mathrm{cm}^{2} / \mathrm{h}\right)$ for individual hydrocarbons was determined at steady state from the slope of cumulative mass per unit area versus time (h) curve. All possible points were used that were at steady state (linear) in each cumulative absorption curve for determination of slopes (Figure 1). The permeability constant $(\mathrm{cm} / \mathrm{h})$ was determined by dividing the steady state flux (slope of cumulative $\mu \mathrm{g} / \mathrm{cm}^{2}$ vs. time curve) by applied surface hydrocarbon concentration. Diffusivity $\left(\mathrm{cm}^{2} / \mathrm{h}\right)$ was obtained by the following relation: $D=L^{2} / 6 \tau$, where $L=500 \mu \mathrm{m}$ (skin

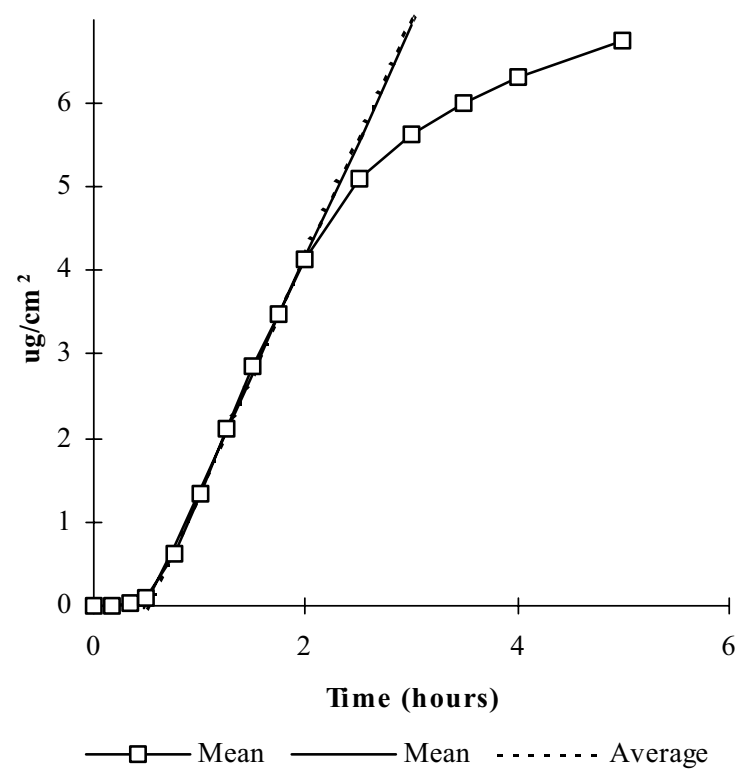

FIGURE 1. Cumulative absorption $\left(\mu \mathrm{g} / \mathrm{cm}^{2}\right)$ versus time $(\mathrm{h})$ plot for $o$-xylene following topical application to 4-d JP-8 preexposed porcine skin sections in in vitro flow through diffusion cells. The best-fit straight line (... average) was used to calculate the flux for this hydrocarbon. 
thickness) and $\tau$ is the lag time obtained by extrapolating the steady-state portion of the curve back to the time or $x$ axis.

Statistical analysis of steady-state flux (Jss), permeability constant, diffusivity, and absorption data were conducted using multiple comparison tests and analysis of variance (ANOVA) with significance level at .05. All analysis was carried out using SAS 8.1 for Windows software (SAS Institute, Cary, NC). A least significance difference (LSD) procedure and Student's $t$ distribution were used for multiple comparisons on all parameters assessed.

\section{RESULTS}

\section{Influence of JP8 Preexposure on the Absorption Kinetics of Aliphatic Hydrocarbons}

Out of eight topically dosed aliphatic hydrocarbons in flow-through in vitro diffusion cells, only four (nonane, undecane, dodecane, and tridecane) were observed in the perfusate samples. Decane and pentadecane were not resolved chromatographically, while tetradecane and hexadecane were not detected in both 1- and 4-d JP-8 preexposed skin flow-through experiments. The total absorption of nonane (154 ng in 1-d and $178 \mathrm{ng}$ in 4-d JP-8 preexposed skin) was significantly greater than that of respective controls (51 ng and 80 ng) (Tables 1 and 2). The steady-state flux and permeability of nonane were significantly greater in both 1- and 4-d preexposed skin than in control skin. These absorption parameters for dodecane and tridecane were statistically significant in 4-d JP-8 preexposure experiments (Tables 1 and 2). The data showed that the total absorption of undecane, dodecane, and tridecane was significantly greater than their respective controls in 4-d preexposed skin, unlike the 1-d preexposed skin, where the difference was nonsignificant. The absorption profiles of dodecane shown in Figure 2 suggest an increased absorption plateau in the 4-d JP-8 preexposed skin over the 1-d preexposed skin, with respect to the control skin. In general, there was a two- to threefold increase in the absorption of nonane and undecane in 1-d while a threeto four fold increase in absorption of dodecane and tridecane was obtained through 4-d JP-8 preexposed skin, when compared to the control skin (Table 3).

\section{Influence of JP8 Preexposure on the Absorption Kinetics of Aromatic Hydrocarbons}

Naphthalene absorption over the entire 5-h perfusion in 1-d JP-8 preexposed skin was $17,818 \mathrm{ng}$, as compared to $10,276 \mathrm{ng}$ in unexposed skin. In 4-d preexposed skin, this was 19,835 ng, with respect to 12,030 ng in control skin. This increase was significantly different in both exposure scenarios (Tables 1 and 2). Similarly, it was evident from these tables that naphthalene flux, permeability, and diffusivity were statistically significant from controls in both preexposures. The total absorption, as well as absorption parameters, for dimethyl naphthalene was statistically different than for controls in 4-d preexposed skin (Table 2). Both naphthalene and dimethyl naphthalene were 
TABLE 1. Mean \pm SEM steady-state flux, permeability, diffusivity, and absorption of jet fuel hydrocarbons in 1-d JP-8 preexposed porcine skin

\begin{tabular}{|c|c|c|c|c|}
\hline Hydrocarbon & $\begin{array}{l}\text { SS Flux } \\
\left(\mu \mathrm{g} / \mathrm{h} / \mathrm{cm}^{2}\right)\end{array}$ & $\begin{array}{l}\text { Permeability } \\
(\mathrm{cm} / \mathrm{h} \times 1000)\end{array}$ & $\begin{array}{l}\text { Diffusivity } \\
\left(\mathrm{cm}^{2} / \mathrm{h} \times 1,000,000\right)\end{array}$ & $\begin{array}{l}\text { Absorption } \\
\text { (ng) }\end{array}$ \\
\hline \multicolumn{5}{|l|}{ Aromatic HC } \\
\hline Naphthalene control & $4.19 \pm 0.36^{b}$ & $0.16 \pm 0.01^{\mathrm{b}}$ & $378 \pm 22^{b}$ & $10276 \pm 1023^{b}$ \\
\hline Naphthalene exposed & $6.60 \pm 0.79^{\mathrm{aA}}$ & $0.26 \pm 0.03^{\mathrm{aA}}$ & $628 \pm 73^{\mathrm{aB}}$ & $17818 \pm 2255^{\mathrm{aA}}$ \\
\hline DMN control & $0.62 \pm 0.10^{\mathrm{b}}$ & $0.02 \pm 0.004^{\mathrm{a}}$ & $178 \pm 10^{\mathrm{a}}$ & $1043 \pm 202^{\mathrm{a}}$ \\
\hline DMN exposed & $0.85 \pm 0.21^{\mathrm{aCD}}$ & $0.03 \pm 0.008^{\mathrm{aD}}$ & $163 \pm 16^{\mathrm{aD}}$ & $1406 \pm 447^{\mathrm{aCD}}$ \\
\hline Ethyl benzene control & $1.04 \pm 0.17^{b}$ & $0.06 \pm 0.009^{b}$ & $715 \pm 75^{b}$ & $1586 \pm 243^{b}$ \\
\hline Ethyl benzene exposed & $3.32 \pm 0.52^{\mathrm{aB}}$ & $0.19 \pm 0.03^{\mathrm{aB}}$ & $1065 \pm 97^{\mathrm{aA}}$ & $3137 \pm 312^{\mathrm{aBC}}$ \\
\hline TMB control & $1.01 \pm 0.14^{b}$ & $0.056 \pm 0.008^{b}$ & $391 \pm 22^{b}$ & $2177 \pm 277^{b}$ \\
\hline TMB exposed & $1.77 \pm 0.21^{\mathrm{aC}}$ & $0.10 \pm 0.01^{\mathrm{aC}}$ & $623 \pm 74^{\mathrm{aB}}$ & $4192 \pm 497^{\mathrm{aB}}$ \\
\hline $\mathrm{CHB}$ control & $0.35 \pm 0.06^{b}$ & $0.018 \pm 0.003^{b}$ & $164 \pm 9.4^{\mathrm{a}}$ & $548 \pm 103^{b}$ \\
\hline $\mathrm{CHB}$ exposed & $0.86 \pm 0.11^{\mathrm{aCD}}$ & $0.045 \pm 0.006^{\mathrm{aD}}$ & $205 \pm 16^{\mathrm{aCD}}$ & $1651 \pm 298^{\mathrm{aCD}}$ \\
\hline o-Xylene control & $1.47 \pm 0.20^{b}$ & $0.085 \pm 0.011^{\mathrm{b}}$ & $710 \pm 105^{b}$ & $2541 \pm 335^{b}$ \\
\hline o-Xylene exposed & $3.80 \pm 0.61^{\mathrm{aB}}$ & $0.218 \pm 0.04^{\mathrm{aAB}}$ & $1013 \pm 23^{\mathrm{aA}}$ & $4765 \pm 490^{\mathrm{aB}}$ \\
\hline \multicolumn{5}{|l|}{ Aliphatic HC } \\
\hline Nonane control & $0.03 \pm 0.01^{b}$ & $0.002 \pm 0.001^{b}$ & $238 \pm 12^{\mathrm{a}}$ & $51 \pm 19^{b}$ \\
\hline Nonane exposed & $0.08 \pm 0.01^{\mathrm{aD}}$ & $0.005 \pm 0.001^{\mathrm{aD}}$ & $342 \pm 75^{\mathrm{aCD}}$ & $154 \pm 11^{\mathrm{aD}}$ \\
\hline Undecane control & $0.07 \pm 0.01^{\mathrm{a}}$ & $0.001 \pm 0.000^{\mathrm{a}}$ & $332 \pm 101^{a}$ & $151 \pm 12^{\mathrm{a}}$ \\
\hline Undecane exposed & $0.16 \pm 0.05^{\mathrm{aD}}$ & $0.003 \pm 0.000^{\mathrm{aD}}$ & $234 \pm 14^{\mathrm{aCD}}$ & $339 \pm 98^{\mathrm{aD}}$ \\
\hline Dodecane control & $0.04 \pm 0.01^{\mathrm{a}}$ & $0.0005 \pm 0.00^{\mathrm{a}}$ & $344 \pm 76^{\mathrm{a}}$ & $81 \pm 18^{a}$ \\
\hline Dodecane exposed & $0.06 \pm 0.02^{\mathrm{aD}}$ & $0.0009 \pm 0.00^{\mathrm{aD}}$ & $356 \pm 107^{\mathrm{aC}}$ & $134 \pm 37^{\mathrm{aD}}$ \\
\hline Tridecane control & $0.02 \pm 0.01^{\mathrm{a}}$ & $0.0003 \pm 0.00^{a}$ & $904 \pm 212^{\mathrm{a}}$ & $46 \pm 16^{\mathrm{a}}$ \\
\hline Tridecane exposed & $0.01 \pm 0.00^{\mathrm{aD}}$ & $0.0002 \pm 0.00^{\mathrm{aD}}$ & $343 \pm 37^{\mathrm{bCD}}$ & $34 \pm 10^{\mathrm{aD}}$ \\
\hline
\end{tabular}

Note. Lower case superscripts indicate significant $(p<.05)$ differences between treatments (control vs. preexposed) within each parameter. Upper case superscripts indicate significant $(p<.05)$ differences among various hydrocarbons.

approximately 1.5 times more absorbed in JP-8 preexposed skin as compared to unexposed skin (Table 3). The benzene-containing hydrocarbons such as ethyl benzene, $O$-xylene, and trimethyl benzene showed a two- and fourfold increase in percutaneous absorption through 1- and 4-d JP-8 preexposed skin, respectively (Table 3). The effect of prolonged JP-8 exposure upon skin was evident by the increased difference from control (naive skin not exposed to JP-8) in absorption profiles of $o$-xylene in $4-d$ preexposed skin compared to $1-d$ preexposed skin (Figure 3). Tables 1 and 2 summarize the statistically significant differences in absorption parameters of ethyl benzene, $o$-xylene, trimethyl benzene, and cyclohexyl benzene in both 1- and 4-d JP-8 preexposed skin experiments, respectively.

\section{Comparative Hydrocarbons absorption Kinetics}

As seen in Tables 1 and 2, the rank order of permeability constants was naphthalene $>o$-xylene $>$ ethyl benzene $>$ trimethyl benzene $>$ cyclohexyl benzene $>$ dimethyl naphthalene $>$ nonane $>$ undecane $>$ dodecane $>$ tridecane in both 1- and 4-d JP8 preexposed skin. Only cyclohexyl benzene permeated less in 4-d than in 1-d preexposed skin. For all components, the rank 
TABLE 2. Mean \pm SEM steady-state flux, permeability, diffusivity, and absorption of jet fuel hydrocarbons in 4-d JP-8 preexposed porcine skin

\begin{tabular}{|c|c|c|c|c|}
\hline Hydrocarbon & $\begin{array}{l}\text { SS Flux } \\
\left(\mu \mathrm{g} / \mathrm{h} / \mathrm{cm}^{2}\right)\end{array}$ & $\begin{array}{l}\text { Permeability } \\
(\mathrm{cm} / \mathrm{h} \times 1000)\end{array}$ & $\begin{array}{l}\text { Diffusivity } \\
\left(\mathrm{cm}^{2} / \mathrm{h} \times 1,000,000\right)\end{array}$ & $\begin{array}{l}\text { Absorption } \\
\text { (ng) }\end{array}$ \\
\hline \multicolumn{5}{|l|}{ Aromatic HC } \\
\hline Naphthalene control & $4.81 \pm 0.36^{\mathrm{b}}$ & $0.19 \pm 0.01^{b}$ & $435 \pm 17^{\mathrm{a}}$ & $12030 \pm 989^{b}$ \\
\hline Naphthalene exposed & $7.57 \pm 0.47^{\mathrm{aA}}$ & $0.29 \pm 0.02^{\mathrm{aA}}$ & $514 \pm 28^{\mathrm{aBC}}$ & $19835 \pm 1453^{\mathrm{aA}}$ \\
\hline DMN control & $0.67 \pm 0.07^{b}$ & $0.03 \pm 0.003^{b}$ & $185 \pm 13^{b}$ & $1179 \pm 155^{b}$ \\
\hline DMN exposed & $0.99 \pm 0.09^{\mathrm{aDE}}$ & $0.04 \pm 0.004^{\mathrm{aE}}$ & $227 \pm 11^{\mathrm{aD}}$ & $2056 \pm 221^{\mathrm{aDE}}$ \\
\hline Ethyl benzene control & $0.61 \pm 0.15^{b}$ & $0.035 \pm 0.009^{b}$ & $870 \pm 61^{\mathrm{a}}$ & $637 \pm 136^{b}$ \\
\hline Ethyl benzene exposed & $2.04 \pm 0.17^{\mathrm{aC}}$ & $0.12 \pm 0.009^{\mathrm{aC}}$ & $834 \pm 54^{\mathrm{aA}}$ & $2594 \pm 250^{\mathrm{aCD}}$ \\
\hline TMB control & $0.49 \pm 0.04^{\mathrm{b}}$ & $0.028 \pm 0.002^{b}$ & $456 \pm 40^{\mathrm{a}}$ & $837 \pm 90^{b}$ \\
\hline TMB exposed & $1.52 \pm 0.10^{\mathrm{aCD}}$ & $0.09 \pm 0.005^{\mathrm{aD}}$ & $670 \pm 124^{\mathrm{aAB}}$ & $3821 \pm 267^{\mathrm{aBC}}$ \\
\hline $\mathrm{CHB}$ control & $0.29 \pm 0.02^{\mathrm{a}}$ & $0.016 \pm 0.001^{\mathrm{a}}$ & $165 \pm 4.4^{\mathrm{b}}$ & $470 \pm 42^{b}$ \\
\hline $\mathrm{CHB}$ exposed & $0.49 \pm 0.07^{\mathrm{aEF}}$ & $0.025 \pm 0.004^{\mathrm{aEF}}$ & $181 \pm 4.6^{\mathrm{aD}}$ & $852 \pm 136^{\mathrm{aEF}}$ \\
\hline o-Xylene control & $1.02 \pm 0.28^{\mathrm{b}}$ & $0.059 \pm 0.016^{\mathrm{b}}$ & $816 \pm 87^{\mathrm{a}}$ & $1156 \pm 263^{b}$ \\
\hline o-Xylene exposed & $3.13 \pm 0.15^{\mathrm{aB}}$ & $0.180 \pm 0.009^{\mathrm{aB}}$ & $806 \pm 86^{\mathrm{aA}}$ & $4865 \pm 340^{\mathrm{aB}}$ \\
\hline \multicolumn{5}{|l|}{ Aliphatic HC } \\
\hline Nonane control & $0.03 \pm 0.01^{\mathrm{b}}$ & $0.002 \pm 0.000^{b}$ & $409 \pm 110^{\mathrm{a}}$ & $80 \pm 15^{b}$ \\
\hline Nonane exposed & $0.07 \pm 0.01^{\mathrm{aF}}$ & $0.005 \pm 0.000^{\mathrm{aF}}$ & $692 \pm 171^{\mathrm{aAB}}$ & $178 \pm 24^{\mathrm{aF}}$ \\
\hline Undecane control & $0.06 \pm 0.01^{\mathrm{a}}$ & $0.001 \pm 0.000^{\mathrm{a}}$ & $308 \pm 52^{\mathrm{a}}$ & $135 \pm 22^{b}$ \\
\hline Undecane exposed & $0.10 \pm 0.02^{\mathrm{aF}}$ & $0.002 \pm 0.000^{\mathrm{aF}}$ & $295 \pm 78^{\mathrm{aCD}}$ & $263 \pm 18^{\mathrm{aF}}$ \\
\hline Dodecane control & $0.02 \pm 0.00^{b}$ & $0.0002 \pm 0.000^{b}$ & $245 \pm 60^{\mathrm{a}}$ & $32 \pm 7^{b}$ \\
\hline Dodecane exposed & $0.05 \pm 0.01^{\mathrm{aF}}$ & $0.0008 \pm 0.000^{\mathrm{aF}}$ & $255 \pm 32^{\mathrm{aD}}$ & $112 \pm 19^{\mathrm{aF}}$ \\
\hline Tridecane control & $0.00 \pm 0.00^{\mathrm{a}}$ & $0.0001 \pm 0.000^{b}$ & $245 \pm 28^{\mathrm{a}}$ & $7.4 \pm 1.9^{b}$ \\
\hline Tridecane exposed & $0.02 \pm 0.01^{\mathrm{aF}}$ & $0.0003 \pm 0.000^{\mathrm{aF}}$ & $222 \pm 18^{\mathrm{aD}}$ & $37 \pm 9.3^{\mathrm{aF}}$ \\
\hline
\end{tabular}

Note. Lower case superscripts indicate significant $(p<.05)$ differences between treatments (control vs. preexposed) within each parameter. Upper case superscripts indicate significant $(p<.05)$ differences among various hydrocarbons.

order of total absorption and steady state flux was similar to that of the permeability constant. There were no statistically significant differences in total absorption and its parameters among aliphatic hydrocarbons for both preexposed time points (Tables 1 and 2). Preexposure also increased the diffusivity constant for all aromatic $\mathrm{HC}$ studied, although such changes did not occur for the aliphatic HC.

\section{Skin Retention of Hydrocarbons}

The fuel hydrocarbons retained in skin as a result of repeated JP-8 application to pigs are presented in Table 4. Out of all studied hydrocarbons, naphthalene, dimethyl naphthalene, and cyclohexyl benzene were found to have significant skin retention in 4-d JP-8 preexposed skin as compared to 1-d preexposed skin.

\section{Stratum Corneum Analysis With FTIR}

FTIR analysis of stratum corneum before and after treatment with selected hydrocarbons shed some light on the possible mechanism of increased hydrocarbon absorption in JP-8 preexposed skin. Emphasis was placed on the peaks, which appeared at approximately 2850 and $2920 \mathrm{~cm}^{-1}$ and were due to symmetric 

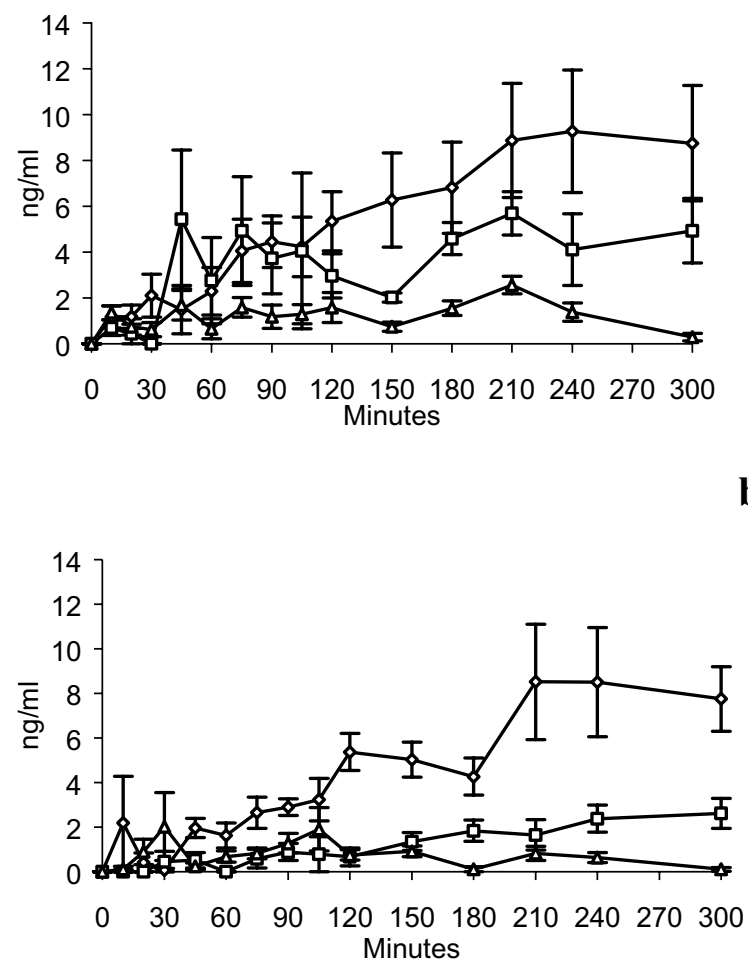

FIGURE 2. Mean perfusate concentrations (ng/ml) of dodecane in (a) 1-d and (b) 4-d JP-8 preexposed porcine skin flow-through experiments. $\square$, Dosing mixture + JP-8 preexposed skin; $\square$, dosing mixture + control skin; $\Delta$, diluent + JP-8 preexposed skin.

TABLE 3. Comparative absorption ratios (mean exposed/mean control values) of different hydrocarbons in 1- and 4-d JP-8 preexposed porcine skin

\begin{tabular}{llc}
\hline & Absorption ratio, & Absorption ratio, \\
Hydrocarbons & $1 \mathrm{~d}$ preexposure & 4 preexposure \\
\hline Naphthalene & 1.73 & 1.65 \\
Dimethyl naphthalene & 1.35 & 1.74 \\
Ethyl benzene & 1.98 & 4.07 \\
Trimethyl benzene & 1.93 & 4.56 \\
Cyclohexyl benzene & 3.02 & 1.81 \\
o-Xylene & 1.88 & 4.21 \\
Nonane & 3.03 & 2.23 \\
Undecane & 2.25 & 1.95 \\
Dodecane & 1.65 & 3.50 \\
Tridecane & 0.74 & 4.90 \\
\hline
\end{tabular}



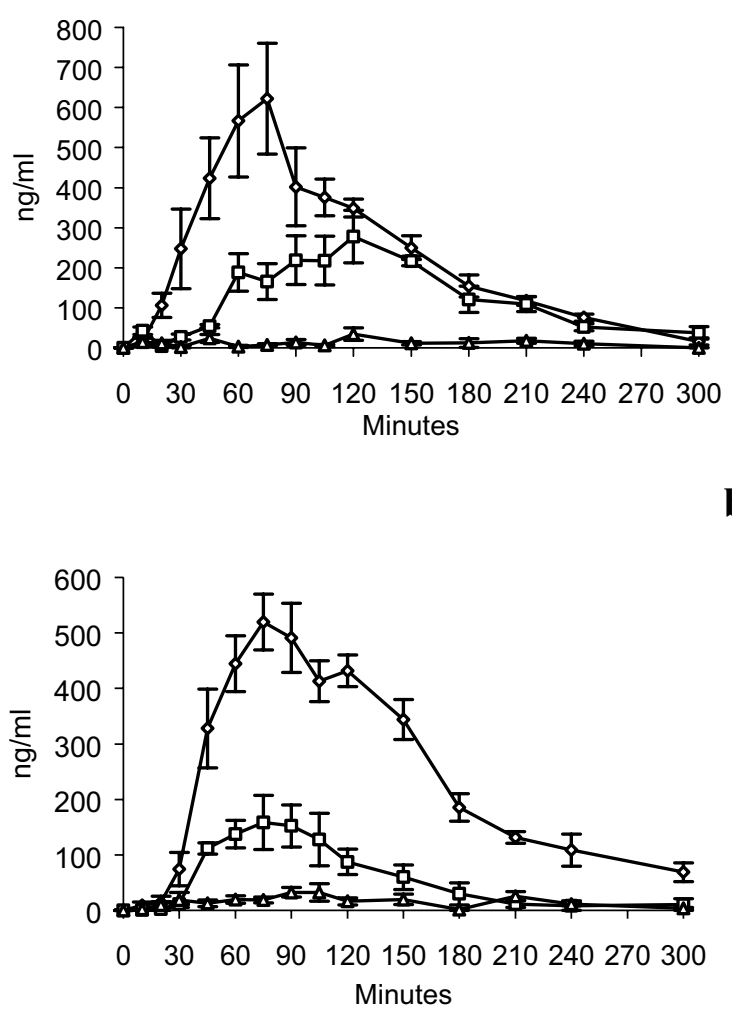

FIGURE 3. Mean perfusate concentrations ( $\mathrm{ng} / \mathrm{ml}$ ) of $o$-xylene in (a) 1-d and (b) 4-d JP-8 preexposed porcine skin flow through experiments. $\square$, Dosing mixture + JP-8 preexposed skin; $\square$, dosing mixture + control skin; $\Delta$, diluent + JP-8 preexposed skin.

and asymmetric $\mathrm{C}-\mathrm{H}$ stretching, respectively. The decrease in $\mathrm{CH}_{2}$ stretching bandwidths, accompanied by a decrease in $\mathrm{CH}_{2}$ band intensity, was observed with most of the aromatic HC (Figure 4) and short-chain aliphatic hydrocarbons. The longer chain aliphatic $\mathrm{HC}$ like tetradecane and hexadecane showed an increase in $\mathrm{CH}_{2}$ stretching peak width and peak shift toward higher wave number (Figures 5 and 6). The dimethyl naphthalene skin retention might be due to accumulation of this $\mathrm{HC}$ in stratum corneum as indicated in Figure 7 , where three peaks $\left(800-650 \mathrm{~cm}^{-1}\right)$ in the dimethyl naphthalene spectrum exactly matched with the SC spectrum after treatment with DMN.

\section{DISCUSSION}

Previously, data showed a dose-related increase in percutaneous absorption of aromatic hydrocarbons like naphthalene and dimethyl naphthalene, 
TABLE 4. Mean \pm SEM comparative retention of different hydrocarbons in 1- and 4-d JP-8 preexposed porcine skin

\begin{tabular}{lcc}
\hline Hydrocarbons & $\begin{array}{l}\text { Skin retention (ng), } \\
1 d \text { preexposure }\end{array}$ & $\begin{array}{l}\text { Skin retention (ng), } \\
4 \text { d preexposure }\end{array}$ \\
\hline Naphthalene & $50.73 \pm 25^{\mathrm{bB}}$ & $416.99 \pm 106^{\mathrm{abA}}$ \\
Dimethyl naphthalene & $0 \pm 0^{\mathrm{bB}}$ & $243.91 \pm 41^{\mathrm{bA}}$ \\
Ethyl benzene & $181.47 \pm 92^{\mathrm{abA}}$ & $284.89 \pm 42^{\mathrm{bA}}$ \\
Trimethyl benzene & $347.10 \pm 106^{\mathrm{aA}}$ & $470.10 \pm 112^{\mathrm{aA}}$ \\
Cyclohexyl benzene & $10.24 \pm 2^{\mathrm{bB}}$ & $36.15 \pm 7^{\mathrm{cA}}$ \\
o-Xylene & $274.07 \pm 97^{\mathrm{aA}}$ & $314.89 \pm 57^{\mathrm{abA}}$ \\
Nonane & $11.12 \pm 4^{\mathrm{bA}}$ & $31.23 \pm 8^{\mathrm{cA}}$ \\
Undecane & $46.16 \pm 15^{\mathrm{bA}}$ & $26.28 \pm 7^{\mathrm{cA}}$ \\
Dodecane & $24.84 \pm 6^{\mathrm{bA}}$ & $14.45 \pm 3^{\mathrm{cA}}$ \\
Tridecane & $14.57 \pm 1^{\mathrm{bA}}$ & $18.71 \pm 5^{\mathrm{cA}}$ \\
\hline
\end{tabular}

Note. Lower case superscripts indicate significant $(p<.05)$ differences among various hydrocarbons within each 1 - and $4-d$ preexposure. Upper case superscripts indicate significant $(p<.05)$ differences between similar hydrocarbons in 1- and 4-d preexposure.

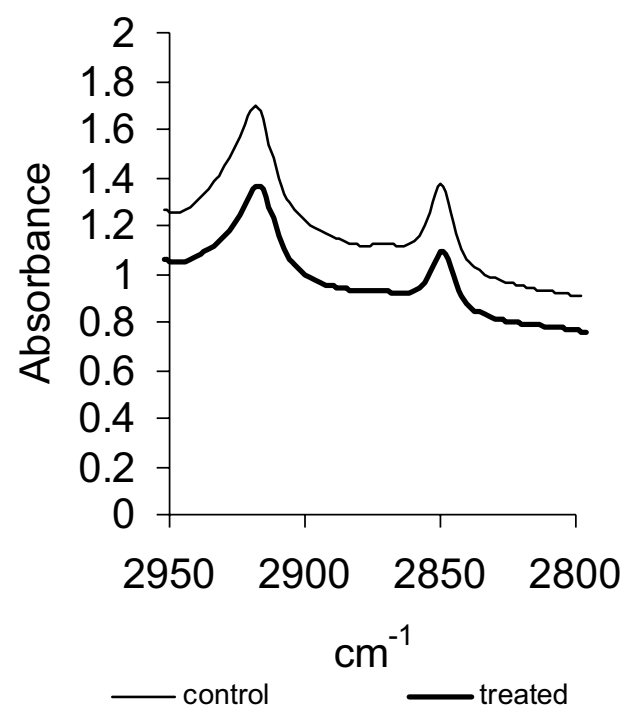

FIGURE 4. FTIR spectrum of porcine stratum corneum before and after treatment with ethyl benzene.

suggesting linear first-order pharmacokinetics (Muhammad et al., 2004). This is critical from the risk assessment point of view, as greater or prolonged exposure to jet fuels may lead to enhanced absorption of such hydrocarbons resulting in local or systemic toxic effects in exposed individuals. These studies prompted us to consider the effect of chronic/repeated skin exposure to jet fuels on a daily basis. There are limited data in the literature regarding prolonged dermal exposure to jet fuels. Upreti et al. (1989) exposed mice to kerosene 15-60 min/d 


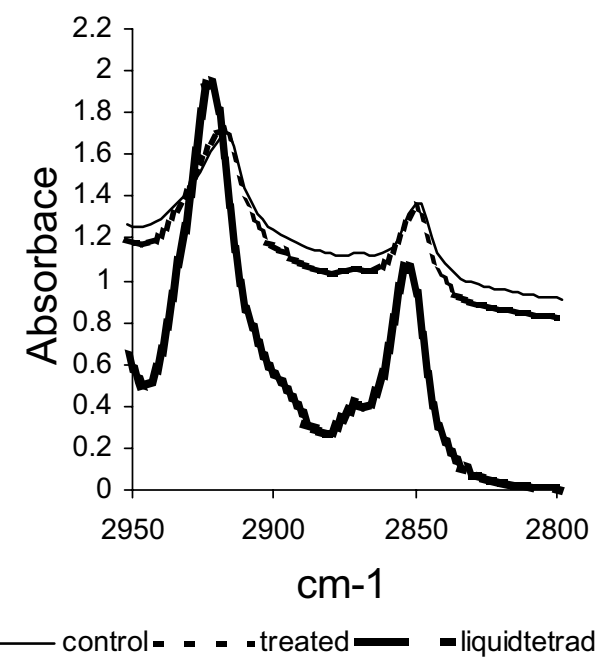

FIGURE 5. FTIR spectrum of porcine stratum corneum before and after treatment with tetradecane, with the spectrum of liquid tetradecane as a reference.

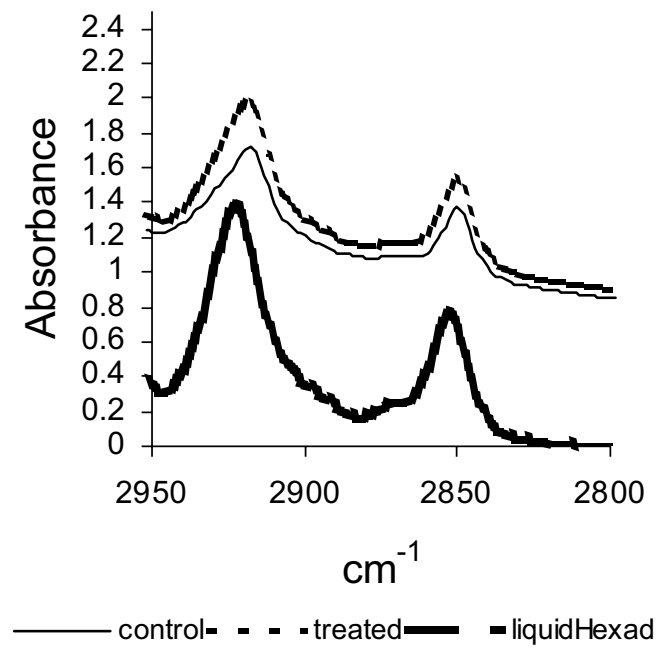

FIGURE 6. FTIR spectrum of porcine stratum corneum before and after treatment with hexadecane, with the spectrum of liquid hexadecane as a reference.

for $7 \mathrm{~d}$ by wrapping the hind feet with a muslin cloth wetted with kerosene and observed systemic consequences of this relatively brief dermal exposure. Ingram et al. (1993) applied 3 kerosenes dermally to mice 3 times/wk for up to $6 \mathrm{wk}$ and found that relative penetration through the skin surface was directly related to the degree of epidermal necrosis observed. There is increasing 


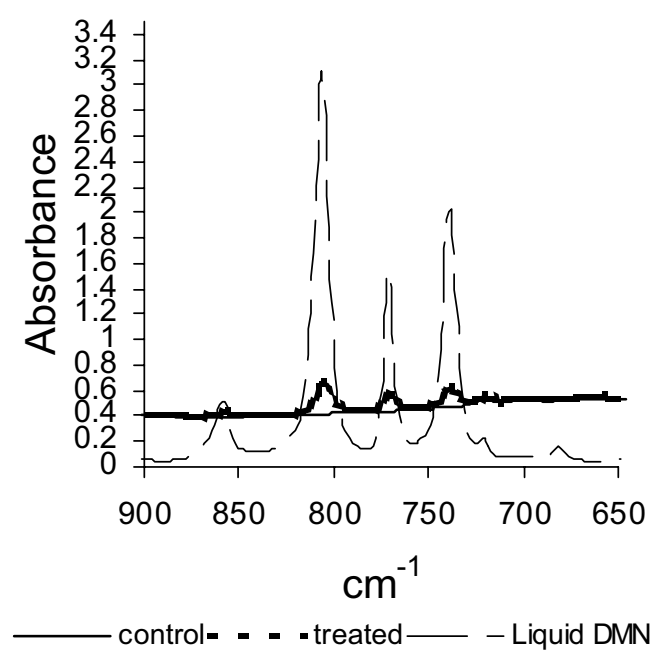

FIGURE 7. FTIR spectrum of porcine stratum corneum before and after treatment with dimethyl naphthalene, with the spectrum of liquid dimethyl naphthalene (DMN) as a reference.

evidence that severe, long-term fuel-induced dermal irritation, necrosis, and regeneration may be integrally related to possible tumorigenesis (McKee et al., 1994; Walborg et al., 1998). Ritchie et al. (2003) suggested that the reduction in the integrity in the dermal barrier by repeated exposure to kerosene-based fuels might increase systemic exposure to other occupational toxicants as well as to toxic components of the fuel itself during subsequent exposures. Therefore, the following hypothesis was tested in this study: "Repeated/preexposure of skin to JP8 jet fuel causes disruption in the skin barrier function by extracting/altering the lipids in the stratum corneum layers or from dermal depots, which lead to an increase in the dermal absorption of hydrocarbons on subsequent exposures."

The results obtained in the present study agree with our hypothesis. Data showed an increase was observed in the absorption of some aliphatic and aromatic HC upon repeated JP-8 exposures to pig skin. The amount of HC absorption was directly proportional to the length of exposure, as a two fold increase was observed in absorption after $1 \mathrm{~d}$ and fourfold increase after $4 \mathrm{~d}$ of JP-8 preexposures with aromatic $\mathrm{HC}$ like ethyl benzene, $\mathrm{o}$-xylene, and trimethyl benzene (Table 3). Similarly, dodecane and tridecane absorbed more in 4-d as compared to 1-d preexposures. These observations are in accordance with Kanikkannen et al. (2001a, 2001b), who stated that disruption of barrier functions of skin after exposure to JP-8 was hypothesized to increase permeation of its own components, or other chemicals exposed to skin. The increased diffusivity of aromatic HC, as well as the FTIR studies discussed laters; supports this hypothesis.

An alternate explanation for this increase in $\mathrm{HC}$ absorption may be that after the previous in vivo exposures, the skin contains levels of aliphatic $\mathrm{HC}$ 
that increase their overall flux/absorption on subsequent in vitro dermal exposure. Since aliphatic $\mathrm{HC}$ are highly lipophilic $\left(\log K_{\mathrm{o} / \mathrm{w}}>5\right)$, they could persist in skin for prolonged periods and could be partitioned out later after SC penetration of polar solvents. This explanation is not appropriate for aromatic $\mathrm{HC}$ as the amount "driven out" of JP-8 preexposed skin with diluent was negligible as compared to what is absorbed (Tables 1 and 2) with dosing mixtures. This is clearly illustrated in Figure 3 for o-xylene. These data suggest a JP-8-induced alteration of the membrane. In these studies, polar solvent (ethanol/water) was used to provide an experimental scenario where $\mathrm{HC}$ absorption is facilitated by altering the lipid milieu so that hydrocarbons in any dermal depot would be absorbed. Solvent extraction and reordering of lipids in the SC from JP-8 exposure reduce the lipophilicity of the SC and appear more likely to enhance the penetration of more hydrophilic molecules such as this polar solvent. As expected, data showed a manyfold increase in absorption of hydrocarbons through unexposed (control) skin with polar solvent in the present study as compared to our previous study with hexadecane (a fuel constituent) as solvent (Muhammad et al., 2004) with similar topical in vitro doses. This increased the sensitivity of the present study design. Dosing of $\mathrm{HC}$ in a polar solvent potentiates absorption compared to dosing in hexadecane, as the vehicle/SC partition coefficient now favors the SC. This process continues as the polar solvent itself is absorbed across the JP-8-damaged barrier and lowers the $\mathrm{SC} /$ perfusate partition coefficient to favor perfusate absorption and thus increased transdermal flux. Mobilization of previously absorbed hydrocarbons with this diluent thus is not responsible for the increased flux seen in these studies.

Out of all the studied $\mathrm{HC}$, aromatics absorbed more efficiently than aliphatic HC (Tables 1 and 2 and Figures 2 and 3), a finding consistent with our previous studies (Riviere et al., 1999; Baynes et al., 2001; Muhammad et al., 2004) and with those of McDougal et al. (2000). Steady-state flux and permeability were statistically different for most studied HC in both 1- and 4-d JP-8 preexposures as compared to controls (Tables 1 and 2), suggesting that JP-8 preexposure produced changes in the barrier functions of skin, thus altering these absorption parameters. Interpreting diffusivity data in skin is complicated by the fact that the stratum corneum is a lipid domain and the viable epidermis is comparably a hydrophilic entity with quasi-liquid-like properties (Potts \& Francoeur, 1991). The variations in diffusivities among various $\mathrm{HC}$ in this study might be due to differences in their lag times. This is evident in Table 1, as the in vitro percutaneous absorption of aromatic $\mathrm{HC}$ is significantly different from the control even after single (1-d) in vivo exposure. Additionally, the computed values of permeability and diffusivity would be affected by previously absorbed compounds mobilized by diluent. As discussed, this might impact aliphatic data more than those of aromatics. These findings suggest that dermal absorption studies through naive skin may not be used to predict percutaneous absorption through fuel preexposed skin, which is the more likely occupational exposure scenario. 
In order to gain insight as to the mechanism for the increase in $\mathrm{HC}$ absorption through JP-8 preexposed skin, FTIR studies were conducted. FTIR spectroscopy provides information on the vibrational modes of stratum corneum lipid layer components and probes the structure on a molecular level (Casal \& Mantsch, 1984). Of particular interest in lipid studies are the IR absorbances near 2850 and $2920 \mathrm{~cm}^{-1}$ due to symmetric and asymmetric methylene group $(\mathrm{H}-\mathrm{C}-\mathrm{H})$ stretching, respectively. Solvent extraction of the SC lipids results in reduction of the methylene group stretching absorbances. Biophysical evidence suggests that stratum corneum lipid domains are the primary barrier to both water loss and the penetration of compounds into the skin (Van Duzee, 1971). The decrease in $\mathrm{CH}_{2}$ stretching bandwidths, accompanied by a decrease in $\mathrm{CH}_{2}$ band intensity, suggests an overall extraction of SC lipids (Levang et al., 1999). Similarly, an overall SC lipid extraction was observed with most of aromatic (Figure 4) and short-chain aliphatic HC in this study. These observations, which are critical to the potentiated absorption hypothesis stated earlier, are also in accordance with Monteiro-Riviere et al. (2004), who found SC delipidization on in vivo exposures of pigs to jet fuels. These authors used transmission electron microscopy (TEM) to study the lipid bilayers of SC after ruthenium tetraoxide staining.

It was not possible to detect long-chain aliphatic $\mathrm{HC}$ in our perfusate samples. One potential explanation is that these highly hydrophobic $\mathrm{HC}\left(\log K_{\mathrm{o} / \mathrm{w}}>5\right)$ could not partition out of SC lipids to be absorbed through the skin (Riviere et al., 1999; Baynes et al., 2001; Muhammad et al., 2004). FTIR was used as a biophysical tool to address this issue. Figures 5 and 6 present the FTIR spectrum of SC before and after treatment with tetradecane and hexadecane, respectively, along with the spectrum of its liquid $\mathrm{HC}$ alone as a reference. It was evident that peak widths and peak heights from tetradecane- and hexadecanetreated SC were higher than those of control SC. A slight peak shift toward greater wave number was also observed in the treated SC. A higher wave number shift in FTIR is an indication of increase in gauche conformers (Potts \& Francoeur, 1993). The broadening of peaks at 2850 and $2920 \mathrm{~cm}^{-1}$ is an indication of increased translational movement or mobility of lipid acyl chains (Naik \& Guy, 1997). On comparison with the reference HC spectra, it was revealed that these peak shifts might be due to binding of these long-chain $\mathrm{HC}$ with the SC lipids. These observations would also support the hypothesis that these long-chain aliphatic $\mathrm{HC}$ may contribute to jet fuel-induced skin irritation.

Another important finding of this study was the formation of dermal depot of certain HC (naphthalene, dimethyl naphthalene, and cyclohexyl benzene) as a result of repeated skin exposures to JP-8 (Table 4). The detection of these $\mathrm{HC}$ in the perfusates from the skin preexposed to JP-8 by topically dosing diluent only suggested that such $\mathrm{HC}$ might have potential for absorption even several days postexposure. Naphthalene, being relatively hydrophilic as compared to the rest of the $\mathrm{HC}$, can partition out of SC into the viable epidermis/dermis (Baynes et al., 2000). Hence it might be assumed that naphthalene could bind/ deposit in the hydrophilic environment of viable epidermis/dermis, thus 
producing persistent residues. It is not known why cyclohexyl benzene was retained in JP-8 preexposed skin. Structurally, cyclohexyl benzene is composed of two benzene rings arranged in a perpendicular plane/axes to each other. This structural configuration might suggest poor absorption through, but strong retention in, the skin. FTIR analysis for dimethyl naphthalene revealed that this $\mathrm{HC}$ could bind/deposit in SC, as shown in Figure 7. This showed that three peaks $\left(900-650 \mathrm{~cm}^{-1}\right)$ of reference dimethyl naphthalene exactly overlapped with the peaks in SC treated with this $\mathrm{HC}$.

In conclusion, our studies indicated a two- to four fold increase in absorption with most of the aromatic and some aliphatic HC through JP-8 preexposed porcine skin. Overall, lipid extraction from the SC by these $\mathrm{HC}$ may be the primary mechanism for this increased absorption as suggested by FTIR. The amount of in vitro percutaneous absorption of such $\mathrm{HC}$ was proportional to the length of in vivo preexposures. Long-chain $\mathrm{HC}$ like tetradecane, pentadecane, and hexadecane may bind in SC as observed with FTIR studies, which may further modulate absorption. Naphthalene, dimethyl naphthalene, and cyclohexyl benzene can form depots/residues in JP-8-exposed skin, capable of further absorption at days postexposure. Polar solvents can enhance the percutaneous absorption of fuel HC. Our results indicate that even single in vivo exposure of skin to JP-8 significantly affects the subsequent in vitro percutaneous absorption of aromatic $\mathrm{HC}$ as compared to absorption through the unexposed (naive) skin. Therefore, single-dose absorption data from naive skin for jet fuel aromatic components may not be optimal to predict the toxic potential for repeated exposures. There is a need to consider the repeated fuel exposure factor in risk assessment studies in occupational settings, as prolonged fuel exposure of skin for $4 \mathrm{~d}$ might significantly affect the absorption of some aliphatic HC compared to their absorption through naive skin.

\section{REFERENCES}

Allen, D. G., Riviere, J. E., and Monteiro-Riviere, N. A. 2000. Induction of early biomarkers of inflammation produced by keratinocytes exposed to jet fuels Jet-A, JP-8, and JP-8 (100). J. Biochem. Mol. Toxicol. 14:231-237.

Allen, D. G., Riviere, J. E., and Monteiro-Riviere, N. A. 2001. Cytokine induction as a measure of cutaneous toxicity in primary and immortalized porcine keratinocytes exposed to jet fuels, and their relationship to normal human epidermal keratinocytes. Toxicol. Lett. 119:209-217.

Baynes, R. E., Brooks, J. D., and Riviere, J. E. 2000. Membrane transport of naphthalene and dodecane in jet fuel mixtures. Toxicol. Ind. Health 16:225-238.

Baynes, R. E., Brooks, J. D., Budsaba, K., Smith, C. E., and Riviere, J. E. 2001. Mixture effects of JP-8 additives on the dermal disposition of jet fuel components. Toxicol. Appl. Pharmacol. 175:269-281.

Bronaugh, R. L., and Stewart, R. F. 1985. Methods for in vitro percutaneous absorption studies: IV. The flow through diffusion cell. J. Pharm. Sci. 74:64-67.

Casal, H. L., and Mantsch, H. H. 1984. Polymorphic phase behavior of phospholipid membranes studied by infrared spectroscopy. Biochem. Biophys. Acta. 779:381-401.

Chou, C. C., Riviere, J. E., and Monteiro-Riviere, N. A. 2002. Differential relationship between the carbon chain length of jet fuel aliphatic hydrocarbons and their ability to induce cytotoxicity vs. interleukin-8 release in human epidermal keratinocytes. Toxicol. Sci. 69:226-233. 
Chou, C. C., Riviere, J. E., and Monteiro-Riviere, N. A. 2003. The cytotoxicity of jet fuel aromatic hydrocarbons and dose-related interleukin-8 release from human epidermal keratinocytes. Arch. Toxicol. 77:384-391.

Freeman, J. J., McKee, R. H., Phillips, R. D., Plutnick, R. T., Scala, R. A., and Ackerman, L. J. 1990. A 90-day toxicity study of the effects of petroleum middle distillates on the skin of $\mathrm{C} 3 \mathrm{H}$ mice. Toxicol. Ind. Health 6:475-491.

Grant, G. M., Shaffer, K. M., Kao, W. Y., Stenger, D. A., and Pancrazio, J. J. 2000. Investigation of in vitro toxicity of jet fuels JP-8 and Jet A. Drug Chem. Toxicol. 23:279-291.

Grasso, P., Sharratt, M., and Ingram, A. J. 1988. Early changes produced in mouse skin by the application of three middle distillates. Cancer Lett. 42:147-155.

Harris, D. T., Sakiestewa, D., Robledo, R. F., Young, R. S., and Witten, M. 2000. Effects of short-term JP-8 jet fuel exposure on cell-mediated immunity. Toxicol. Ind. Health. 16:78-84.

Harris, D. T., Sakiestewa, D., Titone, D., Robledo, R. F., Young, R. S., and Witten, M. 2001. Jet fuel induced immunotoxicity. Toxicol. Ind. Health. 16:261-265.

Ingram, A. J., King, D. J., Grasso, P., and Sharratt, M. 1993. The early changes in mouse skin following topical application of a range of middle distillate oil products. J. Appl. Toxicol. 13:247-257.

Kanikkannam, N., Patel, R., Jackson, T., Shaik, M. S., and Singh, M. 2001a. Percutaneous absorption and skin irritation of JP-8 (jet fuel). Toxicology. 21:1-11.

Kanikkannam, N., Burton, S., Patel, R., Jackson, T., Shaik, M. S., and Singh, M. 2001b. Percutaneous permeation and skin irritation of JP-8 + 100 jet fuel in a porcine model. Toxicol. Lett. 119:133-142.

Levang, A.K., Zhao, K., and Singh, J. 1999. Effect of ethanol/propylene glycol on the in vitro percutaneous absorption of aspirin, biophysical changes and macroscopic barrier properties of the skin. Int. J. Pharma. 181:255-263.

McDougal, J. N., and Rogers, J. V. 2004. Local and systemic toxicity of JP-8 from cutaneous exposures. Toxicol. Lett. 149:301-308.

McDougal, J. N., Pollar, D. L., Weisman, W., Garrett, C. M., and Miller, T. E. 2000. Assessment of skin absorption and penetration of JP-8 jet fuel and its components. Toxicol. Sci. 55:247-255.

McKee, R. H., Amoruso, M. A., Freeman, J. J., and Przygoda, R. T. 1994. Evaluation of the genetic toxicity of middle distillate fuels. Environ. Mol. Mutagen. 23:234-238.

Monteiro-Riviere, N. A., Inman, A. O., and Riviere, J. E. 2001. The effects of short term high dose and lose dose dermal exposure to Jet A, JP-8, and JP-8 + 100 jet fuels. J. Appl. Toxicol. 21:485-494.

Monteiro-Riviere, N. A., Inman, A. O., and Riviere, J. E. 2004. Skin toxicity of jet fuels: ultrastructural studies and the effects of substance P. Toxicol. Appl. Pharmacol. 195:339-347.

Muhammad, F., Baynes, R. E., Monteiro-Riviere, N. A., Xia, X. R., and Riviere, J. E. 2004. Dose related absorption of JP-8 jet fuel hydrocarbons through porcine skin with quantitative structure permeability relationship analysis. Toxicol. Mech. Methods. 14:159-166.

Naik, A., and Guy, R. H. 1997. Infrared spectroscopic and differential scanning calorimetric investigations of the stratum corneum barrier functions. In Mechanisms of transdermal drug delivery, eds. Potts. R. O., and R.H. Guy, and R. H, pp. 87-162. New York: Marcel Dekker.

Panchagnula, R., Salve, P. S., Thomas, N. S., Jain, A. K., and Ramarao, P. 2001. Transdermal delivery of naloxone: effect of water, propylene glycol, ethanol and their binary combinations on permeation through rat skin. Int. J. Pharm. 219:95-105.

Pleil, J. D., Smith, L. B., and Zelnick, S. D. 2000. Personal exposure to JP-8 jet fuel vapors and exhaust at air force bases. Environ. Health Perspect. 108:183-192.

Potts, R. O., and Francoeur, M. L. 1991. The influence of stratum corneum morphology on water permeability. J. Invest. Dermatol. 96:495-499.

Potts, R. O., and Francoeur, M. L. 1992. Physical methods for studying stratum corneum lipids. Semin. Dermatol. 11:129-138.

Potts, R. O., and Francoeur, M. L. 1993. Infrared spectroscopy of stratum corneum lipids: in vitro results and their relevance to permeability. In Pharmaceutical skin permeation enhancement, eds. K. A. Walters and J. Hadgraft, pp. 269-291. New York: Marcel Dekker.

Rhyne, B. N., Pirone, J. R., Riviere, J. E., and Monteiro-Riviere, N. A. 2002. The use of enzyme histochemistry in detecting cutaneous toxicity of three topically applied jet fuel mixtures. Toxicol. Mech. Methods. 12:17-34. 
Ritchie, G. D., Still, K. R., Rossi, J. III, Bekkedal, M. Y. V., Bobb, A. J ., and Arfsten, D. P. 2003. Biological and health effects of exposure to kerosene-based jet fuels and performance additives. J. Toxicol. Environ. Health B 6:357-451.

Riviere, J. E., Brooks, J. D., Monteiro-Riviere, N. A., Budsaba, K., and Smith, C. E. 1999. Dermal absorption and distribution of topically dosed jet fuels Jet-A, Jp-8, and JP-8(100). Toxicol. Appl. Pharmacol. 160:60-75.

Robledo, R. F., Scott, Y. R., Lantz, C., and Witten, M. 2000. Short-term pulmonary response to inhaled JP-8 jet fuel aerosol in mice. Toxicol. Pathol. 28:656-663.

Smith, L. B., Bhattacharya, A., Lemasters, G., Succop, P., Puhala, E., Medvedovic, M., and Joyce, J. 1997. Effect of chronic low-level exposure to jet fuel on postural balance of US Air Force Personnel. J. Occup. Environ. Med. 39:623-632.

Szolar-Platzer, C., Patil, S., and Maibach, H. I. 1996. Effect of topical laurocapram (Azone) on the in vitro percutaneous permeation of sodium lauryl sulfate using human skin. Acta Derm. Venereol. 76:182-185.

Upreti, R. K., Das, M., and Shanker, R. 1989. Dermal exposure to kerosene. Vet. Hum. Toxicol. 31:16-20.

Van Duzee, B. F. 1971. Thermal analysis of human stratum corneum. J. Invest. Dermatol. 65:702-747.

Walborg, E. F., Jr., DiGiovanni, J., Conti, C. J., Slaga, T. J., Freeman, J. J., Steup, D. R., and Skisak, C. M. 1998. Short-term biomarkers of tumor promotion in mouse skin treated with petroleum middle distillates. Toxicol. Sci. 45:137-145.

White, R. D. 1999. Refining and blending of aviation turbine fuels. Drug Chem. Toxicol. 22:143-153.

Zeiger, E., and Smith, L. 1998. The first international conference on the environmental health and safety of jet fuel. Environ. Health Perspect. 106:763-764. 
Copyright of Journal of Toxicology \& Environmental Health: Part A is the property of Taylor \& Francis Ltd and its content may not be copied or emailed to multiple sites or posted to a listserv without the copyright holder's express written permission. However, users may print, download, or email articles for individual use. 
Copyright of Journal of Toxicology \& Environmental Health: Part A is the property of Taylor \& Francis Ltd and its content may not be copied or emailed to multiple sites or posted to a listserv without the copyright holder's express written permission. However, users may print, download, or email articles for individual use. 